This is an unedited manuscript accepted for publication in the Career Development Quarterly.

Please note that the published version will undergo minor additional editing in style and content. Complete reference:

Hirschi, A. \& Freund, P. A. (in press). Career engagement: Investigating intraindividual predictors of weekly fluctuations in proactive career behaviors. Career Development Quarterly.

\title{
Career Engagement: Investigating Intraindividual Predictors of Weekly Fluctuations in Proactive Career Behaviors
}

\author{
Andreas Hirschi* \\ Institute of Psychology, University of Lausanne, Switzerland \\ Department of Management, Leuphana University of Lueneburg, Germany \\ Philipp Alexander Freund \\ Institute of Psychology, Leuphana University of Lueneburg, Germany
}

\begin{abstract}
Author note.
*Correspondence concerning this article should be addressed to Andreas Hirschi, University of Lausanne, Institute for Psychology, Quartier UNIL-Dorigny, Bâtiment Geopolis, CH-1015 Lausanne, Switzerland, Tel: +41 216923289 , E-Mail: andreas.hirschi@unil.ch

Acknowledgement. Part of this research was supported by an individual research grant awarded to Andreas Hirschi by the Deutsche Forschungsgemeinschaft (DFG), GZ: HI 1530/2-1. The funding source had no involvement in study design, in the collection, analysis and interpretation of data, in the writing of the report, or in the decision to submit the article for publication.
\end{abstract}

\section{ABSTRACT}

The present study applies a micro-level perspective on how within-individual differences in motivational and social-cognitive factors affect the weekly fluctuations of engagement in proactive career behaviors among a group of 67 German university students. Career selfefficacy beliefs, perceived career barriers, experienced social career support, positive and negative emotions, and career engagement were assessed weekly for 13 consecutive weeks. Hierarchical linear regression analyses showed that above-average levels of career engagement within individuals were predicted by higher than average perceived social support and positive emotions during a given week. Conversely, within-individual differences in self-efficacy, barriers, and negative emotions had no effect. The results suggest that career interventions should provide boosts in social support and positive emotions.

Keywords: career engagement, diary study, university students, self-directed career management

\section{Introduction}

For several years, the careers literature (Arnold \& Jackson, 1997) has stressed that people need to become increasingly self-directed in their career management, implying a life-long process of proactively shaping one's work experiences. Consequentially, proactive career behaviors (e.g., career planning, networking, or exploration) are essential for attaining objective and subjective career success (e.g., Zikic \& Klehe, 2006). Such career engagement (i.e., the degree to which somebody is proactively exhibiting different career behaviors in order to enhance his or her career development) is therefore of great theoretical and organizational importance. Moreover, career engagement is also increasingly important within 
career counseling practice. Career counseling is more and more moving beyond focusing on career decision-making and is increasingly concerned with getting clients engaged in proactive career management (Greenhaus, Callanan, \& Godshalk, 2010).

However, although both the theoretical and practical importance of career engagement has been demonstrated, the underlying factors that promote career engagement have not yet been clearly established. Cross-sectional and longitudinal studies (e.g., Rogers, Creed, \& Ian Glendon, 2008) have shown that personal (e.g., neuroticism, career decision-making self-efficacy) and environmental factors (e.g., perceived career barriers, social support) affect interindividual differences in career engagement, for example in terms of career planning and exploration. Whereas such previous research is important to explain why some people show higher levels of career engagement than others, the research has its limitations: It only provides information on differences between individuals. For example, if a person receives more social support compared to other people, does she also report more career engagement compared to other individuals? However, in career development theory and practice we are also often interested in what will happen within a given person (i.e., intraindividual processes) and not just across a set of persons (i.e., interindividual processes). For example, a career counselor might wonder whether an increased amount of social support for a given client will lead to increased career engagement for this client. Such knowledge on within-individual change is pivotal for increasing our theoretical understanding of engagement in self-directed career management and for the practice of career interventions. However, the currently available studies do not address what factors affect withinindividual change in career engagement because they focus on between-person effects.

The present study addresses this issue by investigating how intraindividual differences in motivational and social-cognitive factors affect weekly intraindividual changes in career engagement among university students. We specifically examined repeated measures data that were assessed for 13 consecutive weeks regarding the intraindividual effects of career self-efficacy, perceived career barriers, perceived social career support, and experienced positive and negative emotions on within-individual changes in career engagement. In contrast to extant research that investigates traits and relatively stable states as predictors and consequences of career management, we conceptualize career engagement and different motivational and social-cognitive factors as malleable states that can change from one week to the next. Specifically, we are interested in how weekly within-individual deviations from averages in motivational and social-cognitive factors affect weekly fluctuations in career engagement. In this way, this study provides a micro-level perspective of the intraindividual processes that shape an individual's amount of career engagement over relatively short time periods.

\section{Motivational and Social-Cognitive Predictors of Career Engagement}

The selection of the investigated predictor variables of career engagement was based on the view that optimal human development is the result of favorable person-in-context functioning and is situated within a developmental-contextual view of human and career development that sees humans as active, self-regulating, self-constructing living systems (Vondracek, Ferreira, \& Santos, 2010). In line with this perspective, we were interested in selecting predictor variables that represent motivational (Ford, 1992) and social cognitive (Lent, Brown, \& Hackett, 2002) constructs that are empirically established and/or theoretically important to explain inter-individual differences in career management in order to investigate their utility at the within-person level. We selected a set of variables that represent internal as well as external (environmental) aspects and tap into cognitions as well as emotions. Specifically, we selected career self-efficacy beliefs, positive emotions, and perceived social career support as important constructs which are likely to incline people to actively engage in self-directed career management. On the other hand, we chose negative emotions and perceived career barriers as important constructs that would act as avoidance motivators which inhibit active engagement in the task. The next sections will review the literature regarding self-efficacy beliefs, positive and negative emotions, perceived social support, and career barriers in relation to career engagement.

Self-efficacy beliefs. Bandura (1989, p. 1175) stated that "among the mechanisms of personal agency, none is more central or pervasive than 
people's beliefs about their capabilities to exercise control over events that affect their lives". The belief that one is capable of successfully achieving a task is related to increased engagement in the task in terms of both taking on the task and the level of effort and persistence during task execution (Bandura, 2006). King (2004) proposed selfefficacy as an important antecedent to career selfmanagement because people are likely to use career self-managing behavior to a greater extent when they feel competent to do so. Although selfefficacy beliefs can be generalized to represent a more trait-like personality disposition, they usually refer to a specific, task and context, state-like construct (Bandura, 2006). Along this line of thought, it is reasonable to assume that career selfefficacy as a state can show meaningful change within a person from week to week. The positive relations of self-efficacy beliefs to career engagement have been confirmed by a number of empirical studies (e.g., Creed, Patton, \& Prideaux, 2007; Rogers et al., 2008) which show that high school and college students with higher career selfefficacy beliefs also reported more career exploration and planning compared to other study participants.

Emotions. In motivational theories (Ford, 1992) emotions play an important role as an activating force in directing behavior because they energize goal directed activities. This is in agreement with Fredrickson's (2001) "broaden and build" theory of positive emotions. The theory states that positive emotions act as approach motivators, broaden thought-action repertoires, and build intellectual, social, and physical resources, which can be called on in later times of need. This reasoning is supported by different studies which have shown that positive mood and emotions promote proactive behavior and planning (Bindl, Parker, Totterdell, \& HaggerJohnson, 2011) and enable success in a variety of areas (Lyubomirsky, King, \& Diener, 2005), including one's career (Boehm \& Lyubomirsky, 2008). Conversely, negative emotions, such as anxiety and uncertainty, are observed as obstacles for career learning and career identity construction because they inhibit approach behaviors and act as avoidance motivators (Meijers \& Wardekker, 2002). Career research often examines the traitlike disposition to experience positive or negative affect (Judge \& Larsen, 2001). However, emotions frequently change, which makes it important to assess the emotional experience of individuals with short-term assessments (e.g., on a weekly basis as performed in the present study) if we want to understand the micro-level effects of emotions on career development.

Despite their importance, the role of emotions has been frequently neglected in career theory and research, resulting in calls for better integrating emotions in career research (Hartung, 2011; Kidd, 2004). Recent elaborations of SCCT (Lent \& Brown, 2008; Lent et al., 2005) also acknowledged the importance of affect for career development and stated that affectivity has an important effect on well-being in life and work because it affects, among other things, social-cognitive factors such as self-efficacy beliefs. However, most often, career researchers did not consider state emotions but investigated trait-like personal characteristics in terms of positive and negative affectivity or the related personality traits of extraversion and neuroticism. For example, empirical studies (Côté, Saks, \& Zikic, 2006) have shown that positive affectivity positively relates to job search clarity, intensity, and self-efficacy among undergraduate students, whereas trait anxiety and neuroticism are frequently reported as predictors of career indecisiveness (Saka \& Gati, 2007). Neuroticism also negatively relates to career planning and decision-making self-efficacy among adolescents and high school students (Rogers et al., 2008). However, neuroticism and anxiety seem to promote career exploration (Reed, Bruch, \& Haase, 2004; Vignoli, Croity-Belz, Chapeland, de Fillipis, \& Garcia, 2005), contradicting the "broaden and build" assumption and indicating a complex relation of emotions and career management. It is possible that such findings can be explained by differentiating between-person from withinperson effects. Between individuals, higher neuroticism values might be positively related to career exploration because they are related, on average, to engaging in more ruminative exploration. However, within individuals, more negative emotions might inhibit exploratory activities, as implied by the "broaden and build" framework. The present study addresses the call for increased attention to emotions in career development and extends previous studies by focusing on within-person differences in state emotions.

Social career support. From a developmentalcontextual perspective the social context and 
relational aspects in career development must be considered to understand optimal person-incontext functioning (Vondracek et al., 2010). Although many other career choice and development theories have traditionally focused on the individual, the importance of the social environment in career development is increasingly recognized. As an important example, Blustein's (2011) relational theory of working stresses this relational context of careers by stating that working and relationships overlap considerably, with each domain of life affecting the other. He further asserts that the process of career decision making and exploration is facilitated and/or inhibited by relational experiences. Thus, social support acts as an environmental resource and approach motivator that can facilitate career engagement by providing informational, emotional, and tangible support for proactive career management. We assume that perceived support can show meaningful variation from one week to another (e.g., it might be lower than usual if one's partner has been very occupied with her work during the week or higher than usual if a person happened to have a supporting conversation with a close friend that she did not have the chance to talk to for some time). In a qualitative study among undergraduate students, Schultheiss, Kress, Manzi, and Glasscock (2001) showed that social support from family is strongly related to career development issues for this group and is experienced as a facilitating factor, if present, or a hindering factor, if lacking. Quantitative studies (Dietrich \& Kracke, 2009; Kracke, 2002) have also revealed that parental support and child-centered parenting styles are positively related to career exploration for adolescents and that social support generally (i.e., from significant others, peers, or institutions) has similar effects on career exploration and planning for adolescents (Hirschi, Niles, \& Akos, 2011), high school students (Creed, Fallon, \& Hood, 2009; Kenny \& Bledsoe, 2005; Rogers et al., 2008), and unemployed job seekers (Zikic \& Klehe, 2006).

Perceived career barriers. Apart from personal efficacy beliefs, human agency and motivation also depend on a perception of favorable environmental conditions (Bandura, 2006; Ford, 1992). In Social Cognitive Career Theory (Lent, Brown, \& Hackett, 2000), perceived career barriers have been acknowledged as a contextual factor influencing the formation and implementation of career choices. From a developmental-contextual view (Vondracek et al., 2010), people evaluate their environment and their perception of the environment affects motivation and career development processes. Hence, theory and empirical research suggests that it is the perception of the environment that has a strong effect on agency in career development. We assume that the subjective perception of the context and its barriers can show meaningful change within an individual from week to week. Such a perception may depend on the current mood of a person as well as recently obtained or currently recalled information about possible obstacles (e.g., a news report about high unemployment rates among university graduates). Supporting the practical relevance of career barriers, qualitative studies have shown that college students report perceiving different barriers that are personal, social, or labor market specific (Lent, Brown, Talleyrand, et al., 2002; Swanson \& Tokar, 1991). Quantitative research (Lucas \& Epperson, 1990) confirmed that perceived barriers are related to career indecision, lower career expectations (Creed, Conlon, \& Zimmer-Gembeck, 2007), and less career planning among girls low in self-efficacy (Cardoso \& Moreira, 2009).

\section{Purpose of Study}

To summarize, we want to investigate to what extent intraindividual differences in motivational and social constructs act as positive (career selfefficacy beliefs, positive emotions, perceived social career support) or negative (negative emotions, perceived career barriers) predictors of weekly fluctuations in career engagement among university students. We hypothesize that, within individuals:

Hypothesis 1: Higher than average career selfefficacy beliefs have a positive effect on career engagement.

Hypothesis 2: More than average experienced positive emotions have a positive effect on career engagement.

Hypothesis 3: More than average experienced negative emotions have a negative effect on career engagement.

Hypothesis 4: Higher than average levels of experienced social career support have a positive effect on career engagement. 
Hypothesis 5: More than average perceived career barriers have a negative effect on career engagement.

\section{Method \\ Participants and Procedure}

Participants were students from a variety of majors who attended one-semester elective university courses at a German university. In total, $N=67$ students participated in the study, 42 of them $(63 \%)$ were female. Their mean age was 22.61 years $(S D=2.09$ years; range $19-30$ years), 28 participants $(42 \%)$ were $1^{\text {st }}$ year students, 19 $(28 \%)$ were $2^{\text {nd }}$ year students, and the remaining $20(30 \%)$ were $3^{\text {rd }}$ year students.

Students participated in the study as part of their course credit. All students in three elective courses, open to students of all years and majors, were invited to complete a weekly questionnaire over the course of one semester for 13 consecutive weeks and received a weekly email with a link to the survey. The survey was hosted online on a secure webserver and the scales were administered in random order for each student and at each wave. All students who followed the courses participated in the study. However, due to differences in individual participation, not every student completed the questionnaire at each wave. Of the theoretically possible $67 * 13=871$ measurement points across all participants and assessment waves, we collected 521 complete measurement points. On average, we assessed career engagement 9.63 times per person, selfefficacy 9.64 times per person, barriers 9.06 times per person, social support 8.94 times per person, and positive and negative affect 9.63 times per person.

\section{Measures}

Career engagement. Engagement proactive career behaviors was assessed with the Career Engagement Scale (Hirschi, 2011). The measure is similar to other scales (e.g., Strauss, Griffin, \& Parker, 2012) and consists of nine statements. Three describe career management activities in general terms (e.g., cared for the development of your career), whereas the other six tap into single career management behaviors in terms of career planning, career self-exploration, environmental career exploration, networking, human capital/skill development, and positioning behavior. For each statement, students were asked to indicate to what extend they have been engaged in this task during the last week. Answers were indicated on a five-point rating scale ranging from 1 (not much) to 5 (a lot). Previous research (Hirschi, 2011) using the scale has provided support for construct validity by showing significant positive relations to work importance, career decidedness, career self-efficacy, and career exploration among university students. A large scale evaluation study supports the scale's onefactorial structure and discriminant and convergent validity in relation to specific career behaviors and attitudes among three samples of German university students (Hirschi \& Freund, under review). Cronbach's Alpha at the 13 measurement occasions with the present sample ranged from .85 to $.94(M=.90, S D=.03)$.

Career self-efficacy beliefs. We applied the Short Occupational Self-Efficacy scale developed and validated by Rigotti, Schyns and Mohr (2008). Students indicated their agreement to six items (e.g., "Whatever comes my way in my work, I can usually handle it") on a five-point rating scale ranging from 1 (not at all) to 5 (completely). In their evaluation studies (Rigotti et al., 2008), the authors of the scale have reported support for construct validity among large numbers of employees by showing positive relations to job satisfaction, organizational commitment, and job performance. The scale showed a reliability of Cronbach's Alpha in the present sample which ranged from .72 to $.89(M=.83, S D=.05)$.

Emotions. Experienced positive and negative emotions were assessed with the Positive and Negative Affect Scale (PANAS; Krohne, Egloff, Kohlmann, \& Tausch, 1996; Watson, Clark, \& Tellegen, 1988) questionnaire. Students were asked to indicate how often they experienced 10 positive (e.g., attentive, proud) and 10 negative emotions (e.g., hostile, nervous) during the last week on a five point rating scale ranging from 1 (not at all) to 5 (very much). The PANAS is internationally one of the most frequently applied measures of experienced emotions with solid support for construct validity-for example, in relation to depression and anxiety (Crawford \& Henry, 2004). In the present study, Cronbach's Alpha ranged from .80 to $.94(M=.89, S D=.03)$ for positive emotions and from .80 to $.89(M=.86, S D=$ .03) for negative emotions.

Perceived social career support. The amount of perceived social support was assessed with a shortened and adapted four-item version of the University of California, Los Angeles, Social Support 
Inventory (Schwarzer, Dunkel-Schetter, \& Kemeny, 1994). In contrast to the original measure, we focused on career support and did not assess perceived support from distinct sources such as parents, peers, or institutions. In contrast, students were asked how much social support regarding their career development they received during the last week more generally from persons in their environment. They indicated on a 5-point rating scale ranging from 1 (never) to 5 (very often) how often people provided emotional (encouragement, listening and showing understanding), informational, and tangible support. The original scale has been frequently applied in research and received support for positive relations with coping in various life domains (e.g., Wrosch \& Heckhausen, 1999). The adapted scale was administered to a unique sample of 823 students and showed a reliability of $\alpha=.82$ and significant correlations (all $p<.001)$ with career decidedness $(r=.12)$, career self-efficacy $(r=.13)$, career exploration $(r=.32)$, and career engagement $(r=.33)$. In the present sample, Cronbach's Alpha ranged from .64 to .92 $(M=.86, S D=.08)$.

Perceived career barriers. Because no readily available and validated measure of career barriers existed in the German language, we used a deductive item-generation strategy (Hinkin, 1995) and reviewed existing scales measuring career barriers (e.g., Gushue, Clarke, Pantzer, \& Scanlan, 2006; Holland, Daiger, \& Power, 1980). Because lengthy scales can result in carelessness among respondents and can cause practical problems in research settings, we aimed at developing a small number of items that would adequately capture the content domain. We finally adapted six items from existing measures and asked students to indicate to what extent six different factors (external circumstances, family responsibilities, significant others, labor market, general contextual factors, and general economic situation) act as barriers to their career development using a five-point rating scale ranging from 1 (not at all) to 5 (very much). To examine the scale's construct validity, it was administered to a unique sample of 816 students. The results showed an internal consistency of $\alpha=.77$ and support for construct validity by significant correlations (all $p<.01$ ) with career decidedness $(r=-.26)$, career self-efficacy $(r=$ $.16)$, and career planning $(r=-.14)$. Cronbach's Alpha in the present sample ranged from .63 to .84 $(M=.77, S D=.06)$

\section{Descriptive Statistics}

Table 1 shows the means, standard deviations, and zero-order correlations among the variables. The correlations are based on the average scores calculated for every individual (up to 13 measurements per person; $N=67$ ), and for all available single measurement occasions $(N=521)$. Most notably, higher career engagement was significantly correlated with more social support, positive emotions, and fewer career barriers across all measurement occasions, and significantly correlated with social support across person averages.

\begin{tabular}{|c|c|c|c|c|c|c|c|c|c|c|c|c|c|}
\hline & Variable & $\mathrm{M}$ & SD & 1 & 2 & 3 & 4 & 5 & 6 & 7 & 8 & 9 & 10 \\
\hline 1 & Gender & 0.63 & & & & & & -.16 & -.20 & .17 & -.17 & .10 & -.10 \\
\hline 2 & $1^{\text {st }}$ year students & 0.42 & & & & & & -.11 & .08 & -.17 & -.04 & $-.22 *$ & .07 \\
\hline 3 & $2^{\text {nd }}$ year students & 0.27 & & & & & & .15 & $-.21 *$ & $.28 *$ & .11 & $.32 * *$ & .05 \\
\hline 4 & $3^{\text {rd }}$ year students & 0.30 & & & & & & -.03 & .12 & -.09 & -.06 & -.08 & -.02 \\
\hline 5 & Career engagement & 20.83 & 7.92 & $-.22 * *$ & -.04 & .06 & -.02 & & -.01 & .16 & .12 & .16 & $.45^{*}$ \\
\hline 6 & Self-efficacy & 23.13 & 4.44 & $-.37 * *$ & $.13^{* *}$ & $-.21 * *$ & .07 & .03 & & $-.46 * *$ & -.04 & -.15 & .01 \\
\hline 7 & Positive affect & 32.49 & 6.70 & $-.17 * *$ & -.01 & .07 & -.06 & $.21 * *$ & .06 & & $-.31 * *$ & .16 & -.05 \\
\hline 8 & Negative affect & 17.45 & 6.10 & $.16^{* *}$ & $-.14 * *$ & $.24 * *$ & $-.09 *$ & .06 & $-.17 * *$ & $-.31 * *$ & & .13 & $.42 *$ \\
\hline 9 & Social support & 11.66 & 3.76 & $-.10 *$ & .00 & .01 & -.01 & $.38 * *$ & .01 & $.18^{* *}$ & $.16^{* *}$ & & .11 \\
\hline 10 & Barriers & 11.24 & 3.60 & $.17 * *$ & $-.15^{* *}$ & $.30 * *$ & $-.14 * *$ & $.12 * *$ & $-.43 * *$ & $-.09 *$ & $.39 * *$ & $.12 * *$ & \\
\hline
\end{tabular}




\section{Hierarchical Linear Regression Model for Analysis of Repeated Measures Data}

We used multilevel modeling (Stata's procedure xtmixed) for the analysis of the repeated measures data to account for the cluster structure of responses nested within individuals (for a detailed treament of this analysis approach, see RabeHesketh \& Skrondal, 2008). Our model is a random-intercept, random-coefficient model, which assumes normally distributed random components and level-1 residuals, given the covariates included in the model. The full model was specified as

$y_{i j}=\beta_{00}+\beta_{01} X_{1}+\cdots+\beta_{03} X_{3}+\beta_{10} X_{4}+\cdots+$ $\beta_{60} X_{9}+r_{0}+r_{1}+r_{4}+r_{6}+e$,

where $\beta_{00}$ is the intercept in career engagement for all 67 participants in week 1.

At the level of the participants (level 2; timeconstant, person-specific covariates), we included gender and study year as control variables because previous research (McWhirter, 1997; Rogers et al., 2008) has shown that gender can have an effect on social-cognitive career variables such as perceived barriers, self-efficacy beliefs, or social support, and that grade level can affect progress in career development (Rogers et al., 2008). By controlling for those effects we were able to obtain results corrected for their influence, leading to a more precise prediction of the variables of interest. In the equation, $\beta_{01}$ is the estimate for the difference in career engagement between female and male participants, $\beta_{02}$ is the estimate for the difference in career engagement between second and first year students; and $\beta_{03}$ is the estimate for the difference in career engagement between third and first year students.

At the level of the individual responses (level 1; time-varying, person-specific covariates), $\beta_{10}$ is the estimate for the effect of the change in career engagement that a single week evokes (time), $\beta_{20}$ is the estimate for the effect of the change in career engagement that a one-unit increase in self-efficacy evokes, $\beta_{30}$ is the estimate for the effect of the change in career engagement that a one-unit increase in perceived barriers evokes, $\beta_{40}$ is the estimate for the effect of the change in career engagement that a one-unit increase in positive affect evokes, $\beta_{50}$ is the estimate for the effect of the change in career engagement that a one-unit increase in negative affect evokes, and $\beta_{60}$ is the estimate for the effect of the change in career engagement that a one-unit increase in social support evokes. The covariates self-efficacy, barriers, positive and negative affect, and social support were all mean-centered within each individual to provide meaningful parameter estimates with regard to the hypotheses. The covariates all showed meaningful differences between participants and were significantly different from week to week within individuals, as indicated by considerable within-subjects variation.

Table 2 details the results of this model. At a value of 20.88, the intercept in career engagement in week 1 represents the average score for male students in their first year of study. Female students report slightly lower career engagement scores than male students ( $p=.05$ ), and (male) 2nd year students report marginally higher career engagement scores than male 1st year students $(p<.10)$. There is no statistically significant difference between male 1st and 3rd year students. These results show that female and male students differ in their average self-perceived level of career engagement and that students in the second year of study also tentatively tend to report more career engagement.

The parameter estimate of 0.16 for the covariate time indicates that respondents' career engagement rises significantly throughout the semester $(p<.05)$. The results also show that higher than average self-efficacy beliefs do not lead to more career engagement $(p=.37)$, lending no support for Hypothesis 1. Furthermore, an increase in the number of perceived carrier barriers as well as more experienced negative affect do not influence career engagement $(p=.28, p=.31$, respectively), refuting Hypotheses 3 and 5, respectively. However, we do find that more experienced positive affect and better than average social support are both positively related to career engagement (both $p<.001$ ), supporting Hypotheses 2 and 4, respectively. Apparently, if individuals experience positive affect in a given week that is higher than their baseline or receive more social support in a given week than they are accustomed to, their self-reported level of career engagement is also higher than usual.

The parameters $r_{0}, r_{1}, r_{4}$, and $r_{6}$ represent random variation for the intercept, time, positive affect, and social support. These parameters indicate that the respective fixed parameter estimates (intercept, time, positive affect, and 
social support) do not represent all individuals in the sample, suggesting significant variability among individuals, which is supported by the respective confidence intervals not including zero. Adding additional random effects did not lead to an increase in model fit, as checked through likelihood ratio tests. We correlated the predicted values for career engagement at all 521 measurement occasions with the actually reported scores and found a correlation of $r=.86\left(r^{2}=.74\right)$, which shows a close fit between the two variables, suggesting that the model can be used to accurately predict actual career engagement.

\begin{tabular}{|c|c|c|c|c|}
\hline Fixed effects & Parameter & Est. & SE & $\mathrm{p}$ \\
\hline Intercept & $\beta_{00}$ & 20.88 & 1.47 & .00 \\
\hline Female & $\beta_{01}$ & -2.95 & 1.53 & .05 \\
\hline $2^{\text {nd }}$ year & $\beta_{02}$ & 3.03 & 1.80 & .09 \\
\hline $3^{\text {rd }}$ year & $\beta_{03}$ & 0.96 & 1.74 & .58 \\
\hline Time ${ }^{1}$ & $\beta_{10}$ & 0.16 & 0.08 & .04 \\
\hline Self-efficacy ${ }^{2}$ & $\beta_{20}$ & 0.04 & 0.11 & $.36^{3}$ \\
\hline Positive affect ${ }^{2}$ & $\beta_{40}$ & 0.25 & 0.05 & $.00^{3}$ \\
\hline Negative affect ${ }^{2}$ & $\beta_{50}$ & 0.03 & 0.06 & $.31^{3}$ \\
\hline Social support ${ }^{2}$ & $\beta_{60}$ & 0.38 & 0.12 & $.00^{3}$ \\
\hline Barriers 2 & $\beta_{30}$ & 0.07 & 0.13 & $.28^{3}$ \\
\hline Random effects & Parameter & SD & SE & 95\% Conf.Int. \\
\hline Intercept & $r_{0}$ & 5.32 & 0.58 & $4.30-6.59$ \\
\hline Time & $r_{1}$ & 0.34 & 0.09 & $0.20-0.56$ \\
\hline Positive affect & $r_{4}$ & 0.17 & 0.06 & $0.09-0.35$ \\
\hline Social support & $r_{6}$ & 0.43 & 0.13 & $0.24-0.78$ \\
\hline $\begin{array}{l}\text { Within-individual } \\
\text { residual }\end{array}$ & $e$ & 4.52 & 0.17 & $4.19-4.87$ \\
\hline
\end{tabular}

\section{Discussion}

The present study examined whether and how weekly fluctuations in different motivational and social-cognitive variables are related to withinindividual differences in career engagement. The results extend previous research that focused on between-person effects and provide a complementary and micro-level perspective on the phenomenon of self-directed career management.

Our results supported our hypotheses that weekly fluctuations in perceived social support and positive emotions are meaningful related to withinindividual changes in career engagement. First, based on results founded on between-person effects, we expected that more social support acts as a resource that allows people to more actively engage in career management. Our results advance this point by showing that this finding is also observed at a within-person level. If people received more than average degrees of social support during one week, they were also more likely to be more than usually active in career management during that week. This result supports the importance of the social environment of working (Blustein, 2011) and implies that career theory and intervention practice should pay particular attention to the resources that are available to a person in his or her social environment. Our study suggests that it is not only the general level of social support that is important but also the small but meaningful changes in received support, which can vary from week to week.

Second, our results also support the importance of positive emotions for active career management by showing that if students experience more positive emotions than usual during a given week they also increase their level of career engagement during that week. Thus, our study expands previous research by demonstrating that it is not just the general trait of positive affectivity that is important but experienced emotions that might change from week to week that are also significant. The results support the "broaden and build" 
framework (Fredrickson, 2001), which implies that positive emotions broaden thought-action repertoires and build resources that contribute to (career) success (Boehm \& Lyubomirsky, 2008). The results are also consistent with the results from Bindl et al. (2011) who showed that a highactivated positive mood promotes career-related proactive goal regulation among university students and extend this result to within-individual changes in career engagement. Hence, positive emotions seem to facilitate taking on activities that enhance one's career resources by more readily undertaking different behaviors of career management than one normally would.

However, several predictions that were based on findings from between-person effects were not supported at the within-person level. First, previous research (e.g., Rogers et al., 2008) demonstrated that self-efficacy beliefs affect career development in many ways and that compared with other people, people with higher levels of selfefficacy beliefs are more likely to engage in different career management actives. However, our study did not find a significant relation of intraindividual change in self-efficacy with withinindividual differences in weekly career engagement.

Second, we expected that perceived career barriers would inhibit career engagement (e.g., Cardoso \& Moreira, 2009). Our results did not support this assumption at the within-individual level, showing that the longitudinal approach chosen in the present study adds important insight into this topic. Finally, research on the role of negative affectivity, anxiety, and neuroticism (e.g., Meijers \& Wardekker, 2002) suggests that negative affect has detrimental effects on career development and career management on a between-person level. However, our results did not find a meaningful relation between experienced negative emotions and weekly levels of career engagement at a within-person level.

The fact that we could not establish meaningful within-person effects for self-efficacy, barriers, and negative emotions implies that it might be their general level that affects the generally exhibited level of career management, as it compares to other people. Conversely, although changes in selfefficacy beliefs, perceived career barriers, or experienced negative emotions occur from week to week within a person, they seem to have no meaningful effect on whether a person engages in more or less career management than he or she usually does. Possibly, positive emotions and social support have more immediate effects on engagement because activated positive emotions (more so than negative emotions) act as "energizers" of proactive behaviors (Bindl et al., 2011) and social support can provide direct and tangible assistance regarding career tasks (Adler \& Kwon, 2002). Conversely, self-efficacy beliefs and perceived barriers refer to evaluations of personal capability and context and might thus have less of an immediate effect on overt behavior whereas being more relevant for cognitive tasks such as career planning and decision making (Lent et al., 2000 ) that would have a more delayed effect on career behaviors.

Future research could investigate the possibility that those variables exert their effects more in the long term, for example, whether a person engages in more or less career engagement over the course of many months or even years compared with other people. The fact that certain, relatively wellestablished effects on the between person level could not be replicated on a within-person level supports our argument that it is important to pay attention to both levels of analysis.

\section{Limitations}

Several limitations need to be considered when interpreting our results. First, the results are based on a relatively small sample of university students. Due to the practical challenges of diary studies that obtain repeated measures of longitudinal data from study participants, smaller sample sizes are common for this type of analytical approach and the power of our analyses is considerably larger than obtained with equal number of participants in between-subjects designs (Ohly, Sonnentag, Niessen, \& Zapf, 2010). Nevertheless, the small sample implies that the generalizability of the presented results needs to be confirmed with other samples and in different contexts, for example among working adults. Second, due to individual attrition at single assessment waves, we were not able to collect data from every person at every wave. However, our statistical procedure nonetheless allowed us to include all the obtained data by using a full information maximum likelihood estimator, an approach which has been shown to yield very accurate parameter estimates (Graham, 2009). A third limitation is that not all measures showed satisfactory level of internal consistency at each measurement point, although 
low internal consistency $(<.70)$ was only a problem for a total of 3 cases, which represents a proportion of $4 \%(3 / 78)$. Fourth, all measures were obtained by self-reports, which potentially introduces shared method variance that might affect the observed relations among the measures. Therefore, if feasible, prospective studies may consider alternative information sources. Finally, although we assessed a number of withinindividual variables, future research could assess other theoretically important construct, such as outcome expectations, for instance, as predictors of career engagement. Moreover, because this is to our knowledge the first study to assess withinindividual predictors of career engagement, we focus on direct and first-order effects. Elaborating our results, future research could test more complex models including indirect effects of emotions and social-cognitive variables as well as interaction of first- and second order variables (e.g., moderating gender effects).

\section{Career Counseling Implications}

Because our study focused on within-person effects that are particularly relevant in a practical context, the study results have several important implications for career intervention practice. The significant effects of social support and positive emotions suggest that little boosts in social support, as, for example, provided by the counselor or specific career interventions, can have a meaningful and immediate effect on the degree of career engagement of a client. For example, supporting the client in developing a social support network and reflecting on available developmental networks with the client during counseling seems useful. Moreover, facilitating the experience of positive emotions during and through career interventions can be an important treatment component that facilitates active engagement in career management. Such interventions might include, for example, using humor and focusing on experienced positive emotions in work and leisure time during a counseling interview. Conversely, the non-significant effects of self-efficacy beliefs, perceived barriers, and negative emotions are also important to note. For counseling practice this result implies that counselors can still rightfully pay attention to the general level of self-efficacy, perceived barriers, and negative affectivity of a client as they compare to other people. However, our results suggest that small changes in those beliefs, perceptions, and affectivity will not result in meaningful short-term changes of career engagement for a given client. Corresponding career interventions might thus more effectively be tailored as developmental-educative interventions that aim to develop those factors in the long term. For example, interventions could let clients observe role models to increase self-efficacy and focus on developing plans and strategies to overcome and/or avoid career barriers in order to diminish their negative effect. Conversely, focused, short-term, and remedial career interventions might more effectively focus on the immediate increase of experienced social support and positive emotions of a client.

\section{References}

Adler, P., \& Kwon, S. (2002). Social capital: Prospects for a new concepts. Academy of Management Review, 27(1), 17-40.

Arnold, J., \& Jackson, C. (1997). The new career: Issues and challenges. British Journal of Guidance and Counselling, 25(4), 427-434. doi: 10.1080/03069889708253821

Bandura, A. (1989). Human agency in social cognitive theory. American Psychologist, 44(9), 1175-1184. doi: 10.1037/0003-066x.44.9.1175

Bandura, A. (2006). Toward a psychology of human agency. Perspectives on Psychological Science, 1(2), 164-180. doi: 10.1111/J.1745-6916.2006.00011.X

Bindl, U. K., Parker, S. K., Totterdell, P., \& Hagger-Johnson, G. (2011). Fuel of the self-starter: How mood relates to proactive goal regulation. Journal of Applied Psychology. doi: $10.1037 / \mathrm{a} 0024368$

Blustein, D. L. (2011). A relational theory of working. Journal of Vocational Behavior, 79(1), 1-17. doi: 10.1016/j.jvb.2010.10.004

Boehm, J. K., \& Lyubomirsky, S. (2008). Does happiness promote career success? Journal of Career Assessment, 16(1), 101116. doi: $10.1177 / 1069072707308140$

Cardoso, P., \& Moreira, J. (2009). Self-efficacy beliefs and the relation between career planning and perception of barriers. International Journal for Educational and Vocational Guidance, 9(3), 177-188. doi: 10.1007/s10775009-9163-2

Côté, S., Saks, A. M., \& Zikic, J. (2006). Trait affect and job search outcomes. Journal of Vocational Behavior, 68(2), 233-252. doi: 10.1016/j.jvb.2005.08.001

Crawford, J. R., \& Henry, J. D. (2004). The Positive and Negative Affect Schedule (PANAS): Construct validity, measurement properties and normative data in a large non-clinical sample. [Validation Studies]. British Journal of Clinical Psychology, 43(3), 245-265. doi: 10.1348/0144665031752934

Creed, P. A., Conlon, E. G., \& Zimmer-Gembeck, M. J. (2007). Career barriers and reading ability as correlates of career aspirations and expectations of parents and their children. Journal of Vocational Behavior, 70(2), 242-258. doi: 10.1016/J.Jvb.2006.11.001

Creed, P. A., Fallon, T., \& Hood, M. (2009). The relationship between career adaptability, person and situation variables, and career concerns in young adults. Journal of Vocational Behavior, 74(2), 219-229. doi: 10.1016/J.Jvb.2008.12.004

Creed, P. A., Patton, W., \& Prideaux, L. (2007). Predicting change over time in career planning and career exploration for high 
school students. Journal of Adolescence, 30(3), 377-392. doi: 10.1016/j.adolescence.2006.04.003

Dietrich, J., \& Kracke, B. (2009). Career-specific parental behaviors in adolescents' development. Journal of Vocational Behavior, 75(2), 109-119. doi: 10.1016/J.Jvb.2009.03.005

Ford, M. E. (1992). Motivating humans: Goals, emotions, and personal agency beliefs. Newbury Park, CA: Sage.

Fredrickson, B. L. (2001). The role of positive emotions in positive psychology: The broaden-and-build theory of positive emotions. American Psychologist, 56(3), 218-226. doi: 10.1037/0003-066X.56.3.218

Graham, J. W. (2009). Missing data analysis: Making it work in the real world. Annual Review of Psychology, 60(1), 549-576. doi: doi:10.1146/annurev.psych.58.110405.085530

Greenhaus, J. H., Callanan, G. A., \& Godshalk, V. M. (2010). Career management. Thousand Oaks, CA: Sage.

Gushue, G. V., Clarke, C. P., Pantzer, K. M., \& Scanlan, K. R. L. (2006). Self-efficacy, perceptions of barriers, vocational identity, and the career exploration behavior of Latino/a high school students. The Career Development Quarterly, 54(4), 307-317.

Hartung, P. J. (2011). Barrier or benefit? Emotion in life-career design. Journal of Career Assessment, 19(3), 296-305. doi: 10.1177/1069072710395536

Hirschi, A. (2011). Callings in career: A typological approach to essential and optional components. Journal of Vocational Behavior, 79(1), 60-73. doi: 10.1016/j.jvb.2010.11.002

Hirschi, A., \& Freund, P. A. (under review). The career engagement scale: Development and validation of a measure for proactive career behaviors.

Hirschi, A., Niles, S. G., \& Akos, P. (2011). Engagement in adolescent career preparation: Social support, personality and the development of choice decidedness and congruence. Journal of Adolescence, 34(1), 173-182 doi: 10.1016/j.adolescence.2009.12.009

Holland, J. L., Daiger, D. C., \& Power, P. G. (1980). My Vocational Situation. Palo Alto, CA: Consulting Psychologists Press.

Judge, T. A., \& Larsen, R. J. (2001). Dispositional affect and job satisfaction: A review and theoretical extension. Organizational Behavior and Human Decision Processes, 86(1), 67-98.

Kenny, M. E., \& Bledsoe, M. (2005). Contributions of the relational context to career adaptability among urban adolescents. Journal of Vocational Behavior, 66(2), 257-272. doi: 10.1016/j.jvb.2004.10.002

Kidd, J. M. (2004). Emotion in career contexts: Challenges for theory and research. Journal of Vocational Behavior, 64(3), 441-454. doi: 10.1016/j.jvb.2003.12.009

King, Z. (2004). Career self-management: Its nature, causes and consequences. Journal of Vocational Behavior, 65(1), 112133. doi: 10.1016/S0001-8791(03)00052-6

Kracke, B. (2002). The role of personality, parents and peers in adolescents career exploration. Journal of Adolescence, 25(1), 19-30. doi: 10.1006/jado.2001.0446

Krohne, H. W., Egloff, B., Kohlmann, C.-W., \& Tausch, A. (1996). Untersuchungen mit einer deutschen Version der 'Positive and Negative Affect Schedule' (PANAS) [Investigations with a German version of the Positive and Negative Affect Schedule (PANAS)]. Diagnostica, 42(2), 139-156.

Lent, R. W., \& Brown, S. D. (2008). Social cognitive career theory and subjective well-being in the context of work. Journal of Career Assessment, 16(1), 6-21. doi $10.1177 / 1069072707305769$
Lent, R. W., Brown, S. D., \& Hackett, G. (2000). Contextual supports and barriers to career choice: A social cognitive analysis. Journal of Counseling Psychology, 47(1), 36-49. doi: 10.1037/0022-0167.47.1.36

Lent, R. W., Brown, S. D., \& Hackett, G. (2002). Social cognitive career theory. In D. Brown \& Associates (Eds.), Career choice and development (pp. 255-311). San Francisco, CA: Jossey-Bass.

Lent, R. W., Brown, S. D., Talleyrand, R., McPartland, E. B., Davis, T., Chopra, S. B., . . Chia-May, C. (2002). Career choice barriers, supports, and coping strategies: College students' experiences. Journal of Vocational Behavior, 60(1), 61-72. doi: 10.1006/Jvbe.2001.1814

Lent, R. W., Singley, D., Sheu, H. B., Gainor, K. A., Brenner, B. R., Treistman, D., \& Ades, L. (2005). Social cognitive predictors of domain and life satisfaction: Exploring the theoretical precursors of subjective well-being. Journal of Counseling Psychology, 52(3), 429-442. doi: 10.1037/00220167.52.3.429

Lucas, M. S., \& Epperson, D. L. (1990). Types of vocational undecidedness: A replication and refinement. Journal of Counseling Psychology, 37(4), 382-388.

Lyubomirsky, S., King, L., \& Diener, E. (2005). The benefits of frequent positive affect: Does happiness lead to success? Psychological Bulletin, 131(6), 803-855. doi: 10.1037/00332909.131.6.803

McWhirter, E. H. (1997). Perceived barriers to education and career: Ethnic and gender differences. Journal of Vocational Behavior, 50(1), 124-140. doi: 10.1006/jvbe.1995.1536

Meijers, F., \& Wardekker, W. (2002). Career learning in a changing world: The role of emotions. International Journal for the Advancement of Counselling, 24(3), 149-167. doi: 10.1023/a:1022970404517

Ohly, S., Sonnentag, S., Niessen, C., \& Zapf, D. (2010). Diary studies in organizational research. Journal of Personnel Psychology, 9(2), 79-93. doi: 10.1027/1866-5888/a000009

Rabe-Hesketh, S., \& Skrondal, A. (2008). Multilevel and longitudinal modeling using Stata (2nd ed.). College Station, TX: Stata Press.

Reed, M. B., Bruch, M. A., \& Haase, R. F. (2004). Five-factor model of personality and career exploration. Journal of Career Assessment, 12(3), 223-238. doi: $10.1177 / 1069072703261524$

Rigotti, T., Schyns, B., \& Mohr, G. (2008). A short version of the Occupational Self-Efficacy Scale: Structural and construct validity across five countries. Journal of Career Assessment, 16(2), 238-255. doi: 10.1177/1069072707305763

Rogers, M. E., Creed, P. A., \& Ian Glendon, A. (2008). The role of personality in adolescent career planning and exploration: A social cognitive perspective. Journal of Vocational Behavior, 73(1), 132-142.

Saka, N., \& Gati, I. (2007). Emotional and personality-related aspects of persistent career decision-making difficulties. Journal of Vocational Behavior, 71(3), 340-358. doi: 10.1016/j.jvb.2007.08.003

Schultheiss, D. E. P., Kress, H. M., Manzi, A. J., \& Glasscock, J. M. (2001). Relational influences in career development: A qualitative inquiry. The Counseling Psychologist, 29(2), 214239.

Schwarzer, R., Dunkel-Schetter, C., \& Kemeny, M. (1994). The multidimensional nature of received social support in gay men at risk of HIV infection and AIDS. American Journal of Community Psychology, 22(3), 319-339.

Strauss, K., Griffin, M. A., \& Parker, S. K. (2012). Future work selves: How salient hoped-for identities motivate proactive 
career behaviors. Journal of Applied Psychology, 97(3), 580598. doi: $10.1037 / \mathrm{a} 0026423$

Swanson, J. L., \& Tokar, D. M. (1991). College students' perceptions of barriers to career development. Journal of Vocational Behavior, 38(1), 92-106. doi: 10.1016/00018791(91)90020-M

Vignoli, E., Croity-Belz, S., Chapeland, V., de Fillipis, A., \& Garcia, M. (2005). Career exploration in adolescents: The role of anxiety, attachment, and parenting style. Journal of Vocational Behavior, 67(2), 153-168. doi: 10.1016/J.Jvb.2004.08.006

Vondracek, F., Ferreira, J., \& Santos, E. (2010). Vocational behavior and development in times of social change: new perspectives for theory and practice. International Journal for Educational and Vocational Guidance, 10(2), 125-138. doi: 10.1007/s10775-010-9176-x

Watson, D., Clark, L. A., \& Tellegen, A. (1988). Development and validation of brief measures of positive and negative affect: The PANAS scales. Journal of Personality and Social Psychology, 54(6), 1063-1070.

Wrosch, C., \& Heckhausen, J. (1999). Control processes before and after passing a developmental deadline: Activation and deactivation of intimate relationship goals. Journal of Personality and Social Psychology, 77(2), 415-427.

Zikic, J., \& Klehe, U.-C. (2006). Job loss as a blessing in disguise: The role of career exploration and career planning in predicting reemployment quality. Journal of Vocational Behavior, 69(3), 391-409. doi: 10.1016/j.jvb.2006.05.007 
